\title{
Tariff regulation of the integrated water service: an Italian case
}

\author{
F. Cucchiella, M. Gastaldi \& D. Frigioni \\ Department of Electric and Information Engineering, \\ Faculty of Engineering, University of L'Aquila, \\ Monteluco di Roio, 67040 L'Aquila, Italy
}

\begin{abstract}
In the water sector the tariff represents the regulatory service instrument through which the process of convergence between the conditions offered by providers and the conditions desired by collectivity is activated. At the same time the tariff must cover the cost of production and management of the service that overcomes the logic, sustained for far too long in Italy, to furnish an essential resource free of charge. The purpose of this work is to present the economic technical plan of an Optimal Territorial Basin (OTB) for an Italian city (L'Aquila) and the determination of the tariff adopted by the Integrated Water Service (IWS) in the next thirty years. Moreover this plan is able to activate forms of verification and incentive of the technical and economic efficiency that are the basis of water industrial management.
\end{abstract}

Keywords: price cap regulation, water management, network.

\section{Introduction}

The water sector provides an essential service of public utility; therefore it is necessary to guarantee the continuity of the service supply and an elevated qualitative standard to an accessible tariff. It's essential, therefore, that the management of the water resource is efficient and that a suitable system of regulation is used. Law 36/94 "dispositions in subject of water resources" (Law Galli) introduced a new way regarding the management of water services to overcome its fragmentation which is argued as the principal cause of the diseconomies and the dysfunctions of the sector (Barbese and Meucci [1], Caselli and Peruzzi [2]); for water services, it is meant here all those services 
linked with what Law 36/94 calls Integrated Water Service (IWS) i.e. those dealing with supplying - fetching, transporting and distributing - water for domestic use, as well as those dealing with the collection and treatment of wastewater. From here the vertical integration of the service: one single company has to be in charge of the whole water cycle that also includes the sewerages and the treatment, to assemble responsibility and ability of planning and programming. The main objectives of law 36/94 are:

$>$ unification of the management of the service;

$>$ separation of the functions of management;

$>$ planning of the levels of service;

$>$ IWS management following efficiency criteria;

$>$ coverage costs through the tariff.

More specifically it foresees the reorganization of the water services through the constitution of Optimal Territorial Basins (OTB) defined by the Regions and individualized through the territorial and functional integration of the different activities of the integrated cycle (Massarutto [3]). Based on the necessity to industrialize the sector and, at the same time, on the impossibility of avoiding a natural monopoly, the law imposes at least the exploitation of all possible economies of scale and scope, at reaching a competition for the market as a surrogate of the impossible competition in the market. For this reason, a plan must be defined analyzing the pre-existing management, that constitutes however the point of departure of the plan of future management. After the recognition, the plan determinates the targets' project or the necessary interventions to bring the service to that levels of efficiency imposed by the Law and their temporal distribution, estimating both the operational costs and the improvements of the possible effectiveness and efficiency, regarding on the base of the future program of the infrastructural and organizing interventions. The tariff development goes on through a series of operations that allow the adaptation of two different aims: from one side the necessity to bring the level of service to a desired value of efficiency, from the other one the obligation to contain the tariff increases within preset limits with the contemporary coverage of the costs of management (Meucci and Peruzzi [4]). More specifically, the predisposition of the plan can be realized through the following phases showed in Figure 1:

\section{Phase $1 . \quad$ The recognition}

The analysis of the works and the existing infrastructures is necessary to give the service levels that the existing structures are able to assure before the reforming plan began to be implemented, the analysis of the productive capacity, the possible risk sources and precariousness, as well as indications concerning the water balance.

\section{Phase 2. The levels' definition of service}

After the recognition, the territorial Authority will fix the levels of service necessary for the satisfaction of the usage defining the characteristics of the desired service and its quality parameters. The comparison between the existing situation and the desired one allows consideration of the critical situations on 
which it is necessary to intervene with the plan of the investments. It is now possible to give a dimension and a priority to the problems and therefore to define the purpose of every intervention in terms of quantitative and qualitative objectives (Fucci et al. [5]).

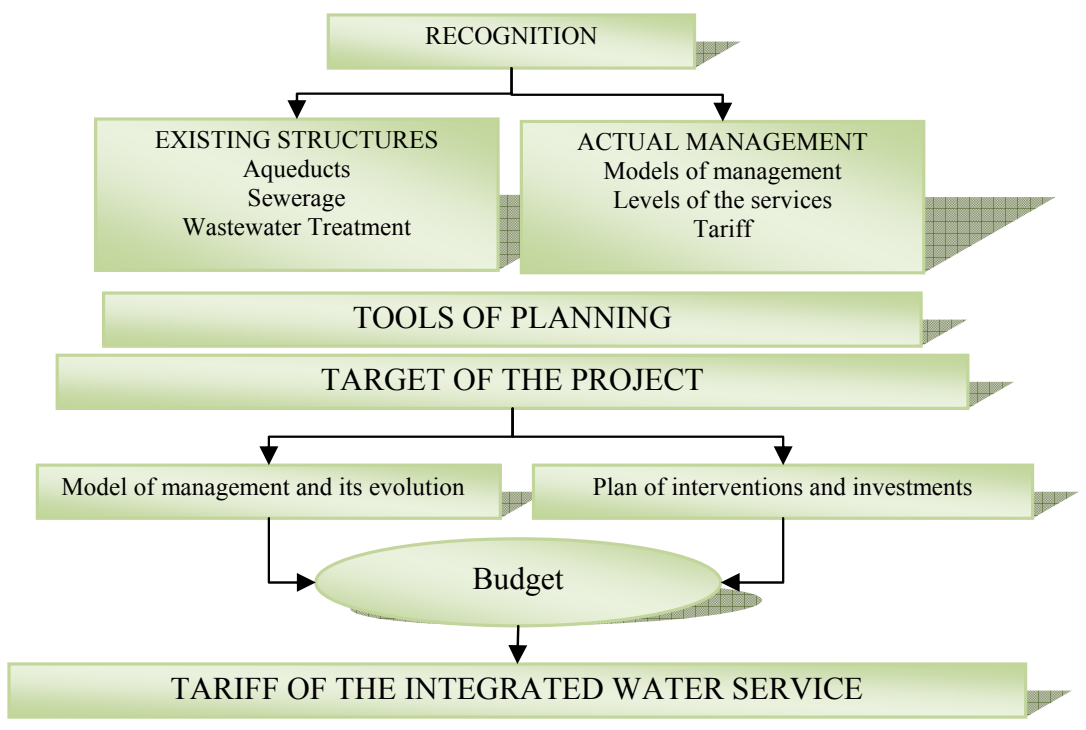

Figure 1: $\quad$ Principal phases for the predisposition of a territorial basin plan.

\section{Phase 3. The planning of the interventions}

The Plan is now able to establish the real program of the interventions and to identify the plan of the investments; these must be realized to fill the difference among the desired levels of service and those that the existing structures can reasonably assure in the period of management. The identification of every intervention is connected to the achievement of specific objective, so that we can evaluate the cost of each operation.

Phase 4. The plan and the tariff development

After the recognition and determination of the project's targets, the analysis of the pre-existing management is required. Considering the operational costs of the first year of the integrated management and the possible improvements of effectiveness and efficiency in the following years, it is possible to identify the operational management costs in the thirty years of the Plan. The aim of the plan is to raise the level of water services, over the period specified by the plan, to that set by the Basin Authority. The tariff development is divided in a series of operations that allows the adaptation of two different purposes: at one side the necessity to bring the level of service to a datum value of efficiency, from the other the obligation to contain the tariff increases within preset limits with the contemporary coverage of the costs of management. 
There are three fundamental actors of the institutional and industrial reorganization of the Integrated Water System: the Region, the Authority of Plan and the Service Administrator (a single enterprise). Galli's Law provides that the Plan has to assign the management of the Integrated Water Service through a series of preliminary operations:

$\checkmark \quad$ The management must be submitted through a convention that answers to the type scheme and to well specified criteria predisposed by the Region.

$\checkmark \quad$ The Authority of Plan, on the base of the convention predisposed by the Region, has to develop some planning and programming activities as the recognition, the plan of the necessary interventions accompanied by a financial plan and connected with the managerial organization model, and finally direct the management control.

This paper can be summarized as follows: in this introduction the fundamental characteristics concerning the depth process of institutional and industrial reorganization of water service, sewerage and treatment determined by the emanation of the law 5/1/94 n. 36, "Dispositions in subject of water resources" are presented; in the second part, the Plan of an Italian case and the program of the interventions that should be realized to filling the difference among the desired levels of service and those of the existing structures are illustrated. Finally in the third part the evolution of a tariff capable of sustaining the execution of the program is presented.

\section{An Italian OTB plan of investments}

Abruzzo Italian Region is divided into 6 OTBs: Pescara, Marsica, Teramo, Peligno Alto Sangro, Chieti and L'Aquila. OTB 1 (L'Aquila) is constituted by 37 Municipalities, it has a surface of $1856 \mathrm{Km}^{2}$, with a resident population of 103995 inhabitants for a density of $56 \mathrm{ab} / \mathrm{Km}^{2}$. Considering the program of interventions that it will realized with precise priorities we can defined the plan of investments that will fill the difference among the desired levels of service and those that the existing structures can assure in the period of management. Such plan with a life of 30 years, foresees investments for a total of 151 millions of Euro.

Figure 2 shows the chronology of the total investments that are more consistent in the first 5 years. It is possible to consider investments for typology of works: external aqueducts, distribution networks, sewerage, treatment and various expenses. The investments in the external aqueducts (including catchment, liftings, telecontrol, ordinary and extraordinary maintenance) are more raised in the first 4 years for the primary necessity to realize new pipes. As it regards the investments in distribution (including counters, network enlargement, tanks, ordinary and extraordinary maintenance), it is preferred to spread the expenses for the construction of a new tank $\left(10.000 \mathrm{~m}^{3}\right)$ between 2015 and 2019 not to already increase the huge investment in the first years of plan. The investments in sewerage (network enlargement and extraordinary maintenance) are enough constant in the time. Crucial points of the economic 
technical plan are the treatment investments defined in the previous Italian plan (Transitional Plans); it has been necessary to compress these investments between 2002 and 2005 (5,5 millions of Euro per year). It can be noticed that the other investments are particularly heavy for the construction of the new head office administrator and for the modernization of the machineries.

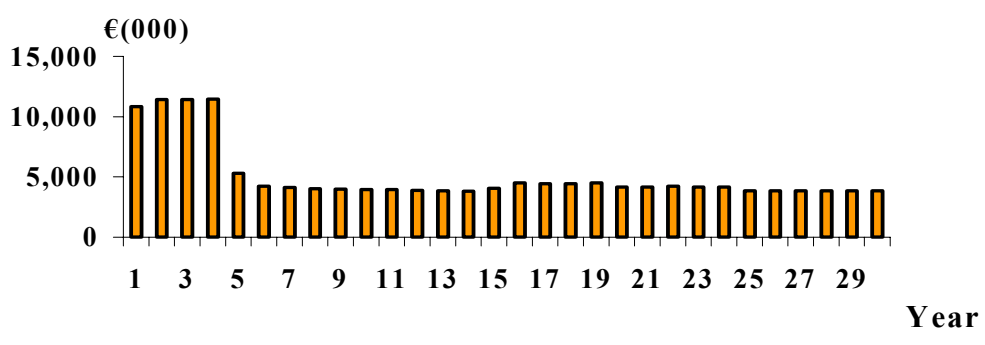

Figure 2: The plan investments.

\section{The development of the tariff Plan}

Once the investments and their temporal distribution have been defined and estimated, the Normalized Method adopted by the Ministry of Public Works with D.M. of 1/08/96 allows the determination of the integrated water service tariff introducing a mechanism of temporal adjustment based on the price-cap method (Passatelli [6], Peruzzi [7], Christopher [8]). This system is based on the principle that the annual tariff increase must be arranged by the administrator and the public authority on the base of the plan of investments (Baldini [9]). The maximum annual increase of the tariff depends to the rate of inflation and also to a parameter that keeps in mind the managerial objectives measured in terms of recoveries of efficiency and attainment of the service standards. The tariff in the current year is given by (Bonanni et al. [10]):

$$
T_{n}=T_{n-1}(1+\pi+K) \quad n=1, \ldots, T ;
$$

where $T_{n-1}$ is the tariff in year $n-1$ function of C, A and $\mathrm{R}$ where $\mathrm{C}$ represents the component of the real operational costs, $\mathrm{A}$ is the component of the costs of depreciation and $\mathrm{R}$ it is the component related to the return of the invested capital, $\pi$ is the annual officially planned inflation rate and $\mathrm{K}$ is the "limit of price". The estimated operational costs of the plan will be compared with the operational reference costs to be able to foresee well determined recoveries of efficiency. The model allows calculation of the tariff and to assure the integral coverage of the investment and management costs estimated in the plan, compared with those of reference. Being (1) a cyclical model, it is necessary to define the point initial $T_{0}$ or rather the pre-existing middle tariff. This is given by the ratio between all the revenues of the pre-existing managements, 
comprehensive of the canons related to wastewaters and the water sold. The Normalized Method foresees that the real average tariff has to immediately make reference to the annual exercise before to the adoption of the financial economic plan of the Integrated Water Service, in exercise from 2002. This method basically requires the following steps (Supervisory Committee on the Use of Water Resources [11]):

$>$ determination of the weighted average tariff of the pre-existing managements (indicated by the abbreviation TMPP), by identifying the invoices sales of these managements and the charges added by the Method unless previously passed on to users;

$>$ identification of management model and consequent quantifying of the amount of project operating costs for the period 2002-2031 (personnel, materials, water purchased electric energy, rentals, leasing, etc.) to be compared with those modelled on the basis of two aims approved by the Method: determination of percent cost reduction to enhance efficiency and the evaluation of the congruence between the plan forecasts and the results of econometric models of the cost of water supply, sewage and treatment;

$>$ identification of annual expenditure an investments, and consequent determination of the component to be charged to depreciation and return on invested capital (a rate of $7 \%$ is applied);

$>$ after comparing the operating costs, depreciation and return on invested capital, the real average tariff is then determined by dividing the three components by the estimated volume supplied;

$>$ the resulting price increase must be contained within a maximum admissible value; should be not the case, the initially planned interventions are remodulated until all the percent tariff increase planned in the project are lower than the maximum allowed ceiling

For the determination of the admissible maximum value of the index percentage of the limit of price $(K)$ the Method (art. 5 of the DM 1/08/96) gives a table of decreasing values in comparison to the value of the tariff related to the preceding year. Such verification is to safeguard the use from increases too elevated tariffs. Then it is necessary to submit the determined tariff development to the last verification required by the Method that it consists in the respect of the "limit of price" established. It proceeds determining, for every year, the relationship between the real tariff of the considered year and that of the preceding year and it is compared with the limit of price, available in the art. 5 of the Method and related to the considered year. The verification has put in evidence the overcoming of the limit $\mathrm{K}$ in different years of the plan, particularly in that years characterized by elevated investments in the treatment sector. The temporal development of the investments and that of the OTB tariff are shown in Figure 3. In the case in examination, therefore, the tariff increases are not contained within the maximum limits of price allowed and this doesn't allow the application of the individualized strategic plan. Such plan foresees investments for a total of over 151 million $€$ in thirty years particularly strong in the first four years; this plan is too strong if compared with the dynamics of the consequential 
tariff entrances. This is due to the following reasons synthetically exposed. First of all it is necessary to notice that the considered OTB has a population density very low; this determines elevated networks lengths in the integrated water service (some municipalities are geographically situated to elevated distance from the Provincial capital and have a population that doesn't often overcome the 200 unities). Besides, part of the distribution networks, report levels of insufficient functionality due to the networks age and of their insufficient state of maintenance; it appears clear, therefore, that is necessary to provide, where possible, to an immediate substitution or maintenance. Finally it observed that the plan, of which to the article 141 of the Law 388/2000 (Financial Law for 2001), foresees strong investments in the depurative sector and in the sewerage system especially in the first four years of the management not completely covered by the tariff development.

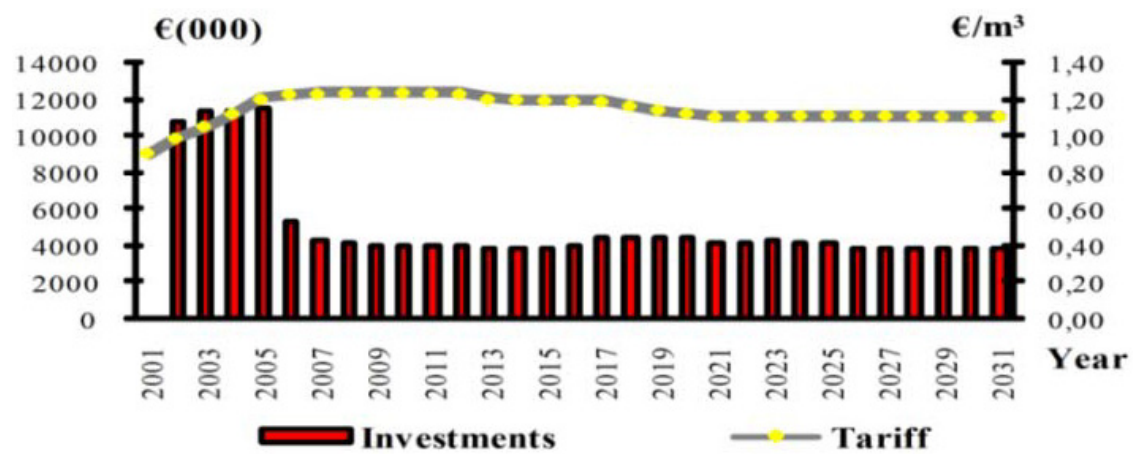

Figure 3: $\quad$ Not user sustainable tariff development.

To allow the verification of the strategic economic plan a regional financing has been proposed in order to cover a substantial part of the investment in the treatment sector. Such financing, around 21 million of euros, allows the not overcoming of the limit of price $\mathrm{K}$ and, in such way, to make the tariff growth sustainable for the customers.

The new comparison between real tariff growth and proposed investment plans assumes the evolution described in Figure 4. Thanks to the regional financing the temporal development of the investments and that of the tariff growth, satisfy both the demands of improvement of the offered service and the necessity to remunerate adequately the activity of the future administrator. Besides, in a period of thirty-year, levels of service are qualitatively and quantitatively reached to resolve the actual criticism of the studied OTB. In Table 1 the fundamental economic characteristics of the Plan for L'Aquila OTB are shown. For brevity the data are related to the first five years of the Plan and those following on a range of five years base. 


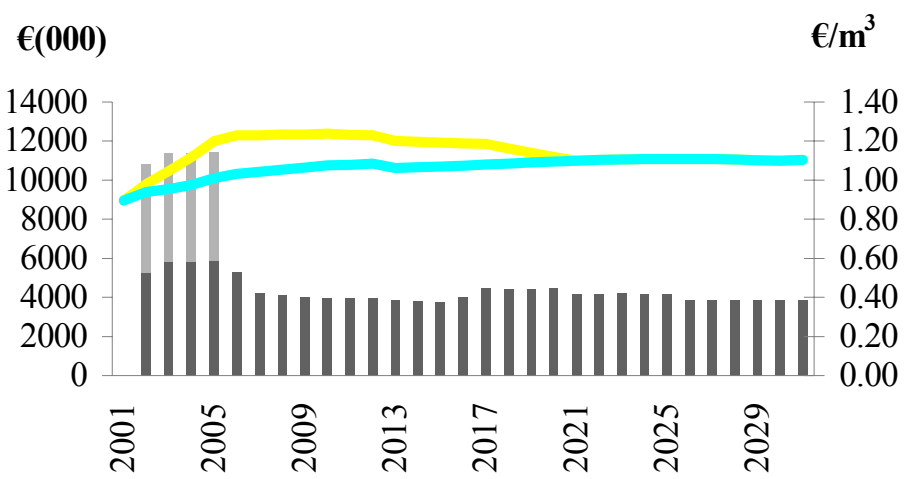

Investments

Regional financing

Tariff without regional financing $\longrightarrow$ Tariff with regional financing

Figure 4: Tariff development, investments and expected regional financing.

Table 1: $\quad$ Economic-financial plan for the Italian case

\begin{tabular}{|l|c|ccccc|}
\cline { 3 - 7 } \multicolumn{2}{l|}{} & 2002 & 2003 & 2004 & 2005 & 2006 \\
\hline Operational costs & $€(000)$ & 11973 & 11710 & 11534 & 11536 & 11362 \\
Amortizations & $€(000)$ & 179 & 368 & 557 & 752 & 1.013 \\
Return of the invested capital & $€(000)$ & 178 & 547 & 923 & 1.287 & 1.616 \\
Total & $€(000)$ & 12329 & 12624 & 13014 & 13575 & 13990 \\
Supplied volume (forecasted) & $\mathrm{m}^{3}(000)$ & 13118 & 13227 & 13336 & 13445 & 13554 \\
Real Tariff & $€ / \mathrm{m}^{3}$ & 0,94 & 0,95 & 0,98 & 1,01 & 1,03 \\
Annual Tariff variation (K) & $\%$ & $4,89 \%$ & 1,55 & $2,25 \%$ & $3,46 \%$ & $2,23 \%$ \\
Maximum annual admitted variation (K) & $\%$ & $7,5 \%$ & $5,0 \%$ & $5,0 \%$ & $5,0 \%$ & $5,0 \%$ \\
Starting Tariff (TMPP) & $\%, 89$ & & & & & \\
\hline
\end{tabular}

\begin{tabular}{|c|c|c|c|c|c|c|}
\hline & & 2011 & 2016 & 2021 & 2026 & 2031 \\
\hline Operational costs & $€(000)$ & 10912 & 10322 & 10092 & 9865 & 9643 \\
\hline Amortizations & $€(000)$ & 1.705 & 2.109 & 2.632 & 3.160 & 3.635 \\
\hline Return of the invested capital & $€(000)$ & 2.586 & 3.275 & 3.979 & 4.413 & 4.571 \\
\hline Total & $€(000)$ & 15203 & 15706 & 16703 & 17438 & 17849 \\
\hline Supplied volume (forecasted) & $\mathrm{m}^{3}(000)$ & 14099 & 14643 & 15188 & 15733 & 16169 \\
\hline Real Tariff & $€ / \mathrm{m}^{3}$ & 1,08 & 1,07 & 1,10 & 1,11 & 1,10 \\
\hline Annual Tariff variation $(\mathrm{K})$ & $\%$ & $0,33 \%$ & $\begin{array}{c}0,25 \\
\%\end{array}$ & $0,36 \%$ & $-0,01 \%$ & $0,37 \%$ \\
\hline Maximum annual admitted variation $(\mathrm{K})$ & $\%$ & $5,0 \%$ & $5,0 \%$ & $5,0 \%$ & $5,0 \%$ & $5,0 \%$ \\
\hline
\end{tabular}

With reference to tariff evolution during the plan period, it should be noted that there is a further confirmation of the initially growing and later stable trend of the intertemporal tariff profile due to the combination of two factors: on the one hand, the concentration of interventions in the first four years after the assignment of the integrated water service and on the other hand the pricing 
mechanism which, for two components out of three, is linked to the net accounting value computed for the completed works.

\section{Conclusions}

In this paper a model of management of the Integrated Water Service has been introduced. Such model represents one of the pilot projects in Italy. In fact, although the actual legislation is complete, the managerial model is still incomplete (Muraro [12] and Marra [13]). This plan represents therefore a pilot project that can be followed by the other Optimal Territorial Basins. To conclude our paper a geographical analysis can be performed to illustrate the results of tariff mechanism in 41 Basin Plans in Italy (Figure 5). Compared with absolute tariff levels it is observed that the values in the South and in the Islands are on average higher than in the other basins of the country (Supervisory Committee on the Use of Water Resources, [11]). The possible reasons for this difference may be the different forecast project operating costs which, in some situations, represent the only tariff based charges. Our contacts with the regional authorities evidenced many subjective elements, which confirm that the willingness to implement the presented reform is widespread, even if not unanimous. Finally, the last governments have explicitly taken a stand in favour of the Integrated Water Service reform and have promised to accelerate it by studying and introducing some relevant procedural simplifications. Moreover the effort to increase the use of project financing in Italy looks promising, also in the water sector. At the same time, some concern must be expressed for several particular initiatives taken by municipalities and other institutions, which aim, by using the project financing, at building new infrastructures for the water service without following the procedures set out by Law 36/94: such initiatives may indeed postpone or even hinder the real implementation of the reform.

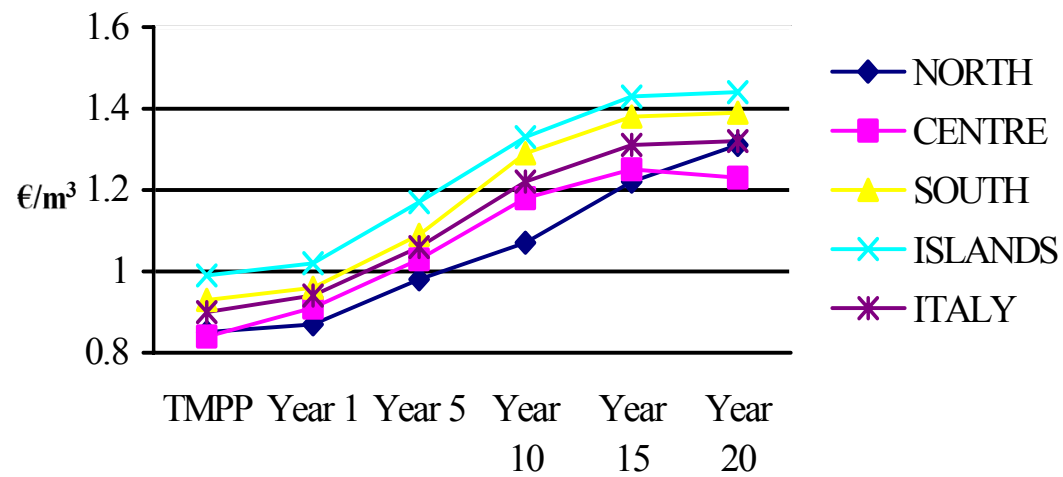

Figure 5: $\quad$ Tariff development per reference geographical area. 


\section{References}

[1] Barbese, E. and Meucci, F., Note sulla salvaguardia, coordinamento e integrazione di funzioni (ex art. 9, comma 4, legge 36/94), Papers Proaqua, Report Number 8, 1997.

[2] Caselli, R. and Peruzzi, P., Servizi idrici fra regolazione e mercato, Papers Proaqua, Report Number 19, 1998.

[3] Massarutto, A., Il ciclo integrato delle acque. Regole di mercato e modelli operativi a confronto, Franco Angeli, 2001.

[4] Meucci, F. and Peruzzi, P., Manuale del Piano di Ambito per il Servizio Idrico Integrato, Franco Angeli, 1998.

[5] Fucci, G., Lubello, C. and Meucci, F., Livelli di servizio - Descrizione, analisi e commento dei livelli di servizio per i Piani delle Autorità di Ambito, Papers Proaqua, Report Number 15, 1998.

[6] Passatelli, M., Struttura della regolamentazione tariffaria in applicazione della legge 36/94, Report Number 1, 1995.

[7] Peruzzi, P., Le tariffe dei servizi idrici, Papers Proaqua, Report Number 7, 1996.

[8] Christopher, M. G., Logistics and Supply Chain Management; strategies for reducing costs and improving services, London, Pitman Publishing, 1992.

[9] Baldini, D., Il finanziamento degli investimenti nel settore idrico, Papers Proaqua, Report Number 37, 2001.

[10] Bonanni, A., Gastaldi, M. and Rocca, C., Riorganizzazione e gestione del Servizio Idrico Integrato, Franco Angeli Editore, 2003.

[11] Supervisory Committee on the Use of Water Resources, Annual Report to Parliament on the State of the Water Service, 2003.

[12] Muraro, G., Water services and water policy in Italy, in Sustainable Development and Environmental Management Experiences and Case Studies (Clini, Musu and Gullino Eds.), Springer Netherlands, 65-90, 2008.

[13] Marra A., Internal Regulation by Mixed Enterprises: the case of the Italian Water Sector, Annals of Public and Cooperative Economics, Vol. 78, No. 2, 245-275, 2007. 